\title{
Effects of the Loading and Unloading Conditions on Crack Propagation in High Composite Slope of Deep Open-Pit Mine
}

\author{
Zhiguo Chang $\left(\mathbb{D},{ }^{1,2}\right.$ Qingxiang Cai $\mathbb{D}^{1},{ }^{1}$ Wei Zhou $\mathbb{D}^{1},{ }^{1}$ Izhar Mithal Jiskani $\mathbb{D}{ }^{1}$ \\ and Rui Wang $\mathbb{B}^{1}$ \\ ${ }^{1}$ School of Mines, China University of Mining and Technology, Xuzhou, Jiangsu 221116, China \\ ${ }^{2}$ School of Mining and Geological Engineering, Xinjiang Institute of Engineering, Urumqi, Xinjiang 830000, China \\ Correspondence should be addressed to Qingxiang Cai; qxcai@cumt.edu.cn and Wei Zhou; loutian1982@126.com
}

Received 25 January 2019; Accepted 12 May 2019; Published 28 May 2019

Academic Editor: Abdul Aziz bin Abdul Samad

Copyright (C) 2019 Zhiguo Chang et al. This is an open access article distributed under the Creative Commons Attribution License, which permits unrestricted use, distribution, and reproduction in any medium, provided the original work is properly cited.

In the process of open-pit excavation and stacking of dump along the side wall, the rock mass inside the composite slope undergoes complicated loading and unloading effect, which are manifested as triaxial stress $\rightarrow$ horizontal unloading $\rightarrow$ axial loading. In this study, a corresponding mechanical model of crack propagation in composite slope under loading and unloading effects was established. The stress-strain curves and deformation characteristics of rock under different stress paths were studied. A series of different tests under unloading pressure condition were carried out to study the behavior of the rock fracture under different confining pressure paths. The results showed that under the same initial stress conditions, the deviator stress required for rock unloading failure was less than that of the conventional triaxial compression. The axial deformation of rock samples was gradually increased with the increase of unloading, and the unloading easily led to rock failure. By analyzing the crack propagation mechanism under loading and unloading stress field, the analytic relation of the limit height of the composite slope with the crack morphology as the variation was determined when crack propagation occurred near the slope surface. This study provides a technical note on local damage and cracks propagation of a fractured rock mass under the loading-unloading effects in high composite slope.

\section{Introduction}

Rock mass fracture damage caused by unloading excavation has always been a topic of high consideration in the rock mechanics $[1,2]$. The rock in the crust is compressed under the action of gravity and tectonic force of the overlying rock mass. Once the slope surface is exposed, the rock propagates along the direction of load reduction, creating tensile cracks or causing the cracks to expand along the vertical tension direction $[3,4]$. For the initial construction stage of a deep open-pit coal mine, the stripped material is used to be dumped outside the open pit. To reduce the transportation distance and cost, most of the external dumps are located along the side wall of the open pit. The depth of mining increases with continuous excavation. Simultaneously, the dumping height is also gradually increased and results in the formation of a deep steep composite slope consisting of mining and dumping slope. Due to increasing pit depth, the issues concerned with slope stability in the open-pit mines are of high concerns as it can influence the productivity and longevity of the mine [5]. As open pit gets increasingly deeper, it becomes more critical to understand in detail the stress distribution of high-steep composite slopes. The factors affecting the deformation and stability of the composite slope are not only the stress concentration caused by the unloading effect of the slope excavation but also the loading effect on the slope by the external dump. It implies that the composite slope is affected by horizontal unloading and vertical loading simultaneously. The increasing composite slope height caused by excavation and dumping can lead to several adverse stress conditions. Under the action of loading and unloading, the stress redistribution near the slope surface causes some structural surfaces or weak parts to deform and expand. Such damage can lead to continuous creep and expansion of discontinuous surfaces ultimately progressing from local deformation to macroscopic failure. 
The systematic study of the unloading effect of rock excavation began in the 1970s to meet the needs of underground nuclear waste storage construction, deep mining, and deep tunnel excavation [6-8]. After loading and unloading tests of rock mass with joints and fractures under different stress paths, Huang et al. [9] pointed out that there exists an initial stress in the natural rock mass. The excavation of rock mass leads to the stress release, which makes the stress redistribution in the rock mass. For rock mass with structural planes such as joints and fissures, it still has good mechanical properties when loading, and once it is subjected to unloading, especially when the tensile stress appears in the rock mass caused by unloading, the mechanical properties of rock mass change, which lead to the rapid deterioration of the rock mass [10]. After triaxial compression tests under conventional and unloading conditions, Kaiser et al. [11] observed that the mechanical properties of rock mass are different under loading and unloading conditions, especially the changes caused by excavation and unloading are more complex in rock engineering. Chen et al. [12] compared rock salt dilatancy behaviors under triaxial unloading confining pressure tests with conventional uniaxial and triaxial compression tests. Fu et al. [13] analyzed the instability mechanism of working face with large mining height under the unloading stress field. The coal mining process is the unloading process of coal and rock, and the stress field is transformed into the unloading field consisted of the initial stress and unloading stress; Cao et al. [14] studied unloading vibration induced by a high initial stress release during underground excavations by investigating the mechanical behavior and permeability of coal rock under different degrees of unloading confining pressure and reloading axial stress by a triaxial experimental apparatus. In [15], it was revealed that peak deviatoric stress of coal rock is lower than that in a conventional triaxial compression test, and the peak deviatoric stress linearly relates the degree of unloading confining pressure. Huang et al. [16] developed an idea that it is inappropriate to use the mechanical parameters obtained under loading conditions to calculate and analyze the deformation and slope stability during the excavation and unloading process. The results may vary from actual situation and cause hidden engineering and safety problems. These research findings have promoted the application and development of unloading rock mechanics to an extent.

At present, by theoretical analyses [17], laboratory tests $[18,19]$, and numerical simulations [20], lots of research results have been attained in the excavation unloading effect and the loosening mechanism, the law of excavated slope deformation, the crack propagation and the relationship between the unloading capacity and mechanical parameters, and so on [21-23]. According to the work presented in $[24,25]$, mechanisms of large-scale slope failure process are driven by the preexisting discontinuous structure and the propagation of brittle tensile cracks, which are attributed to the unloading effect of rock excavation. Herrero [26] evaluated the impact of premining stress and excavation depth on the stability of jointed rock mass and pointed out the high-stress amplitude and stress redistribution caused by excavation sequence can promote rock damage and fracture propagation, leading to slope instability. By analyzing the stress distribution in hard rock slope, Martin [27] concluded that slope failure may be more and more dominated by new stress-induced cracks growing linearly with the excavation depth when stress magnitudes increase. As the depth of excavation increases, the stress values parallel to the slope surface get larger, and combining with the low stress in the vertical direction close to the surface, it can lead to progressive failure. Kalkani [28] examined the excavation unloading effect in rock wedge stability analysis and discovered the horizontal in situ stress has a major influence on the stress distributions in slopes. Stacey et al. [29] determined the relationship between in situ stress and pit depth, as well as the occurrence of extended strain regions in the slope. They also found that as the slope of the pit becomes higher, the stress concentration combined with in situ stress and the high induced stress at the slope toe should be considered in the slope stability analysis. Therefore, the unloading factor should be considered in the rock engineering analysis. By this way, it can further describe the excavation characteristics of complex unloading rock engineering.

The main purpose of this research is to quantify the effect of composite slope height and stress distribution on slope stability. This is done by studying the expansion process of the internal cracks in slopes, which can gradually reduce the strength of brittle rock masses and contribute to slope failure. The main objectives to achieve this goal include numerical simulation of stress distribution inside composite slopes, triaxial compression test of rock under different stress paths, fracture mechanism of crack under loadingunloading conditions, and establishment of a discriminant of the ultimate height for the composite slope.

\section{Stress Distribution in the Composite Slope}

According to the formation mechanism, the slope can be divided into natural slope and artificial slope. Generally, the generation of in situ stress in slope is related to various dynamic movements of the earth, including the gravity stress, extrusion, magma pouring, and so on. After a longterm geological tectonic movement and surface natural weathering, the internal stress field of the rock mass undergoes a series of loading and unloading repeated actions, forming a stress field mainly composed of self-weight stress and residual stress, which is basically in equilibrium. However, the engineering construction activities undertaken by humans, including the cutting of the original natural slope (such as highway cutting slope and open quarry slope), the excavation of the original stratum (such as open-pit mining slope, well roadway, and tunnel) and the accumulation of artificial soil and rock (such as dumps and tailings dams), not only destroyed the original surface shape but also disturbed the original geostress equilibrium state.

For deep open-pit mines, the stripping of rock is essentially the horizontal stress unloading while the dumping along the open-pit side wall is vertical stress loading. During the excavation of slope, the lack of effective solid support in the direction of the free surface leads to the loss of the lateral 
restraint, and a large area of the unloading zone is formed. The rock mass may undergo unloading rebound deformation and instability along the direction of stress loss, while the stacking of dump along the side slope is essentially a gradual loading process of vertical stress.

Compared with natural slope, artificial slope has the characteristics of short excavation time, high strength, fast in situ stress release, and drastic stress state change. With the continuous excavation of open-pit slope and the stacking of side-slope dump, the high-steep composite slope undergoes complex stress dynamic change of horizontal unloading and vertical loading, and the in situ stress needs to be adjusted continuously to adapt to the change of slope shape. With the increase of the overall height of the composite slope, stress concentration is easy to occur at the bottom of the composite slope, and the higher the height, the more obvious the deformation and damage caused by the stress concentration.

In this section, a composite slope of nonworking slope in Beitashan Pasture Open-Pit Mine (BP Mine) is taken as a prototype for numerical simulation to analyze the distribution and evolution of mining stress and cracks under loading-unloading conditions. BP Mine, located at Zhundong coal basin, is the largest of the four coal basins in Xinjiang, China, where a number of closely located lignite open-pit mines are being operated. BP Mine has a surface area of $50.87 \mathrm{~km}^{2}$ and mining depth ranging from $78-83 \mathrm{~m}$. A single coal seam, with a dip angle of less than 5 degrees, extends in the NW-SE direction. The main overburden strata consist of horizontal stratified topsoil and sandstone of $30 \mathrm{~m}$ thickness, respectively. The bedrock lies at the bottom of the coal seam and consists of thinly bedded underclay and grey crystallized limestone. Excavation of this mine has recently been initiated at the northwest border of the mining district and is progressing towards the southeast. After the open-pit mine was excavated, the stripped materials are transported by fixed road on the nonworking wall to the spoil area located on the side wall at the NW of the current pit, gradually forming a high-steep composite slope as seen in Figure 1.

Table 1 demonstrates the material properties for each geologic layer in the study area.

The stratum condition of the open-pit mine is simple. The purpose of this numerical simulation is to analyze the stress distribution law. Therefore, the actual slope is simplified when the model is established. According to geological conditions and initial mining parameters, FLAC3D has been used to simulate the stress distribution of slope under the conditions of open-pit excavation and dumping along the side. The typical individual bench geometry consists of $10 \mathrm{~m}$ bench height with $14 \mathrm{~m}$ bench width, finally forming a side wall with an overall height of $80 \mathrm{~m}$. The artificial boundaries on both the left and the right sides of the model are set away from the surface of the slope, which should not be less than the overall height of the slope, i.e., $80 \mathrm{~m}$. The surface of the slope is assigned as a free boundary, while the nodes on the four vertical boundary surfaces, at $X=0, X=380 \mathrm{~m}, Y=0$, and $Y=100 \mathrm{~m}$, are not allowed to be horizontally displaced. In addition, the nodes on the bottom boundary at $Z=0$ are fully constrained but

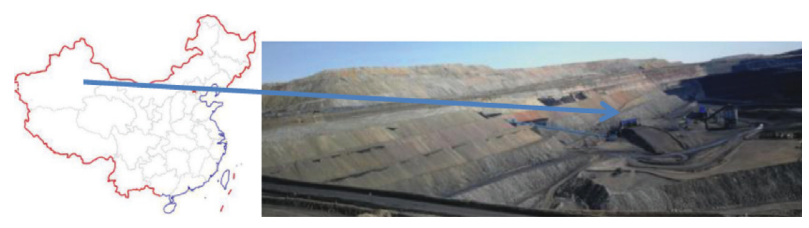

FIgUre 1: Compound slope of BP Mine.

free in the tangential direction or horizontal direction along $Z$-axis. The displacement constraints of all boundaries in the numerical model are rigid. A Mohr-Coulomb material model is initially defined for all zones and the initial stress state is applied with gravity acting in the positive $z$-direction. The dumping height of $45 \mathrm{~m}$ is used, and according to the average bulk density of the stripped material, the self-weight stress is converted to the corresponding uniform load of $0.9 \mathrm{MPa}$ in the range of $X=70 \sim 160, Y=0 \sim 100$, and $Z=130$ at the top of the model. The stress distribution of the slope under the dumping along open-pit side wall is obtained, as shown in Figure 2.

Figure 3(a) shows that after the excavation of deep openpit mine, the artificial slope with multibenches is gradually formed. As the slope is excavated by benches, the residual stress of the rock mass inside the slope is gradually released, which breaks the original horizontal stratification of the vertical ground stress. The rock near the slope shows a stress distribution parallel to the slope, while the rock away from the slope gradually attains the stress state of the rock itself. On the basis of excavation, the vertical stress distribution at the top of slope under the uniform load equivalent to the gravity of the dumping site at the height of $45 \mathrm{~m}$ is simulated as shown in Figure 3(b). The original stress balance has been broken through the formation of the dump, and a saddleshaped stress concentration area is formed in the slope. Thus, as the slope excavation and dumping are stacked, the composite slope undergoes complex internal stress changes. The stress state changes from the original three-directional compression to bidirectional or unidirectional compression, or even local tensile stress area may also occur.

According to the stress distribution and degree of rock mass damage, the original stress in the region I, the axial loading in region II, and the radial unloading in region III are formed after the excavation of the slope as shown in Figure 4 . The more closer to the slope surface, the more significant the stress changes occur, whereas far from the surface (such as the rock mass in the region I) almost no or slight changes occur. In intermediate region II, excavation and dumping cause the rock to gradually change from threedimensional stress state to quasi-three-dimensional stress state or bidirectional stress state. The quasi-threedimensional stress state here refers to the stress perpendicular to the slope surface gradually decreases and finally tends to be bidirectional.

For the rock mass closest to the slope surface in region III, the instantaneous release of the lateral constraint is equal to applying a reverse tensile stress on the initial stress and gradually decreasing to 0 . The stress state is from three directions. The force shifts to two-way force, and the excavation unloading effect can be decomposed into a joint 
TABle 1: Properties of each geologic layer.

\begin{tabular}{lccccc}
\hline Stratum & Young's modulus $(\mathrm{GPa})$ & Poisson's ratio & Mass density $\left(\mathrm{kg} / \mathrm{m}^{3}\right)$ & Cohesion $(\mathrm{MPa})$ & Angle of internal friction $\left(^{\circ}\right)$ \\
\hline Topsoil & $1.80 \times 10^{-2}$ & 0.3 & 1786 & 13.4 & 21.3 \\
Sandstone & 8.30 & 0.214 & 2245 & 28.6 & 25.6 \\
Coal & 0.65 & 0.36 & 1540 & 13.0 & 20 \\
Limestone & 6.11 & 0.224 & 2130 & 27.0 & 22.5 \\
\hline
\end{tabular}

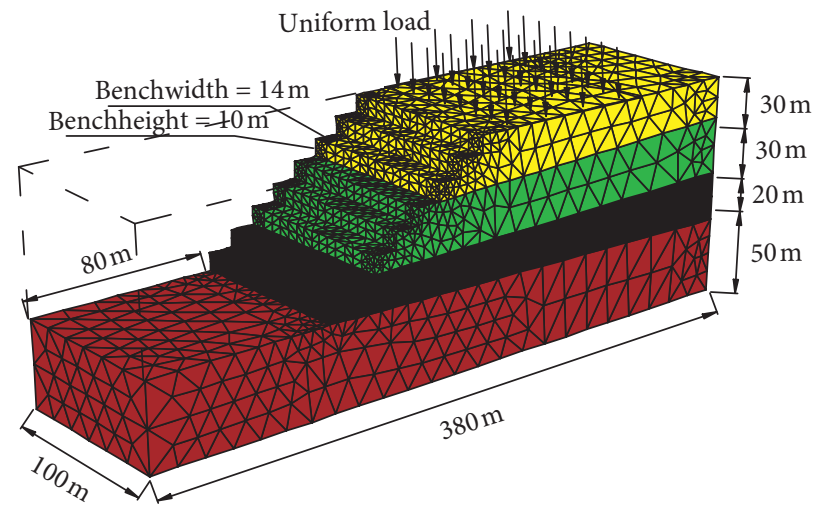

Figure 2: Details of modeled geometry.

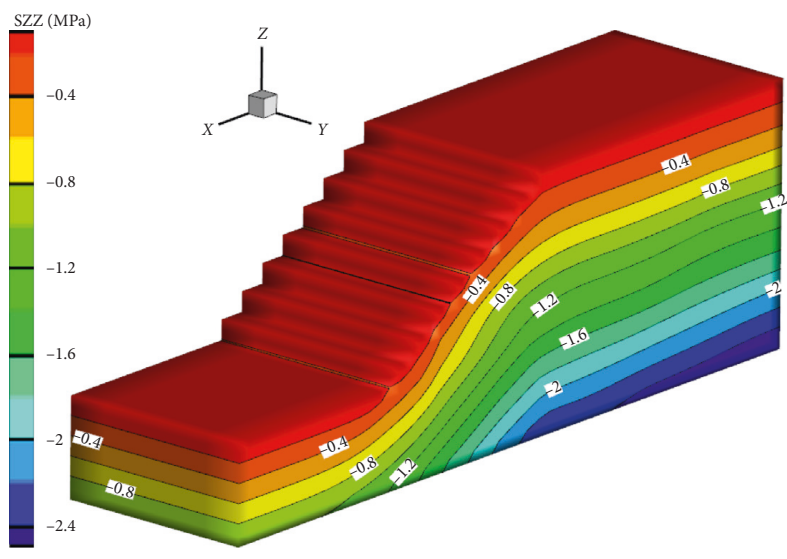

(a)

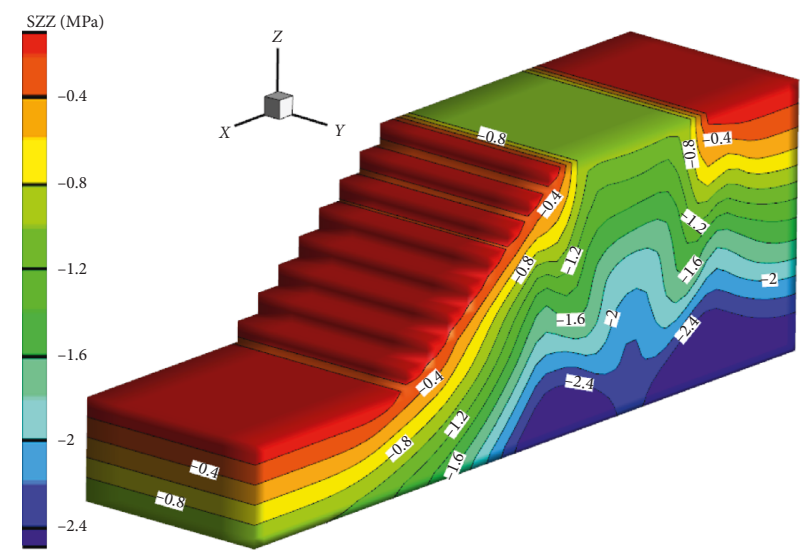

(b)

Figure 3: Vertical stress of slope. (a) No dumping. (b) Dumping.

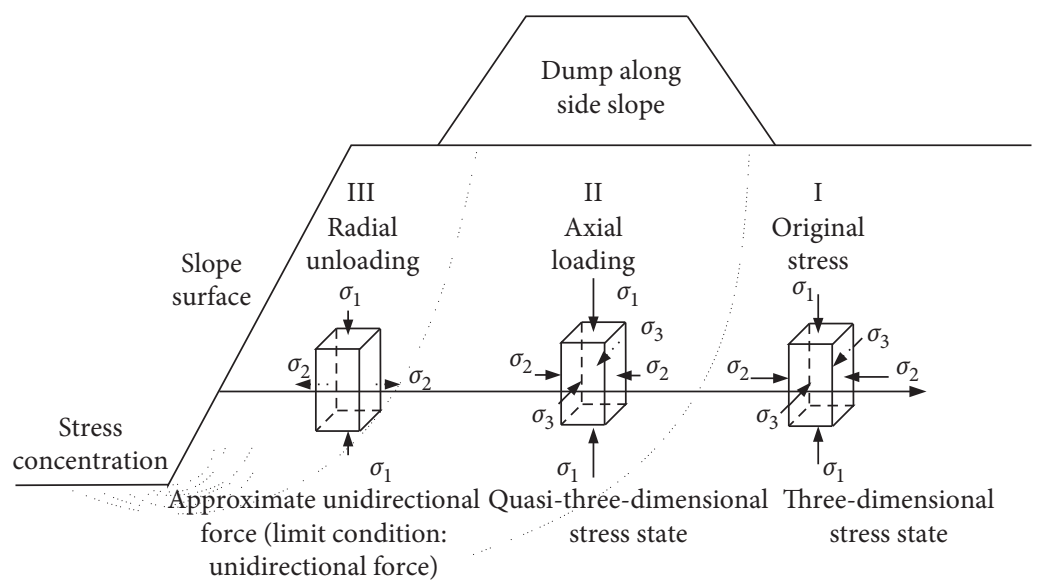

Figure 4: The stress distribution of composite slope. 
action model of initial stress and mining unloading stress, as shown in Figure 5, where $\sigma$ is the vertical stress, $\lambda$ is the lateral pressure coefficient, and $\Delta \sigma$ is the unloading stress.

From region I to III, the shear stress in the rock mass increases with the gradual decrease in horizontal confining pressure; especially at the bottom of the slope, the gravity stress reaches the maximum level, while the confining pressure is minimal, which leads to the formation of the shear stress in the concentration zone where the slope is most vulnerable to shear failure. At the same time, due to the compression stress of the upper steps, the rock mass near the slope surface in the region III undergoes lateral deformation, and it is subjected to tensile stress due to plastic deformation of the internal rock mass. The redistributed stress field causes tensile or shear failure of the rock mass at the slope surface, destroying its structural integrity or the stress concentration in the original cracks, causing the rock mass fracture failure.

\section{Laboratory Compression Tests}

According to the stress distribution of composite slope (Figure 4), the uniaxial compression tests, conventional triaxial compression tests, and triaxial compression tests under the unloading confining pressure condition were carried out, respectively, to simulate the stress state of rock in region I to III to study behavior of the rock fracture under different confining pressure paths. The core samples selected for the studies were taken at depth of $60 \mathrm{~m}$ from a slope in BP Mine. The samples were processed into standard cylinders of $50 \mathrm{~mm}$ in diameter and $100 \mathrm{~mm}$ in height. The allowable deviation of the surface roughness was $+0.05 \mathrm{~mm}$, and the end faces perpendicular to the axis of the specimen with an allowable deviation of $+0.25^{\circ}$. The tests were carried out using MTS815 Rock Tester to measure the axial and circumferential strain of the specimen. The conventional triaxial compression tests were performed in a straincontrolled way at a constant displacement loading rate of $2 \times 10^{-3} \mathrm{~mm} / \mathrm{s}$, while the triaxial unloading confining pressure tests adopted a stress-controlled way with the axial loading rate of $0.5 \mathrm{MPa} / \mathrm{s}$ and unloading confining pressure rate of $0.1 \mathrm{MPa} / \mathrm{s}$.

First, the uniaxial compression tests in region III and the conventional triaxial compression tests in the region I were carried out to obtain the sandstone strength, deformation parameters, and the deformation and failure characteristics under the loading conditions. Considering the depth of the rock sample $(60 \mathrm{~m})$, the confining pressure was set as $5 \mathrm{MPa}$. The typical stress-strain curves and damaged rock samples are shown in Figures 6(a), 7(b), and 7(c). The peak strength of sandstone under uniaxial compression is $65 \mathrm{MPa}$, while the one under the triaxial compression condition can reach $110 \mathrm{MPa}$ with the confining pressure of $5 \mathrm{MPa}$. It indicated that the confining pressure has a great influence on the rock strength. Firstly, the confining pressure enhances the compressive strength of the rock, and secondly, it causes the failure mode to change from uniaxial splitting failure to triaxial shear failure.

Experimenting with the same material under different paths of unloading confining pressure may yield different

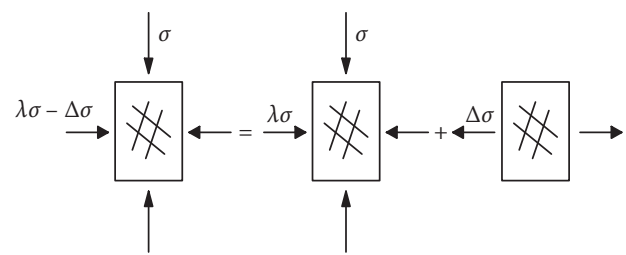

FIgURE 5: The equivalent unloading stress field.

results. This is one of the major reasons for the divergence of the unloading tests. According to the axial load variation law, the unloading paths can be divided into the increasing axial pressure with decreasing confining pressure $(\mathrm{OB}$ in Figure 8, with the dashed line for nonlinear strength criterion), the constant axial pressure with decreasing confining pressure (OC in Figure 8), the unequal decrease in axial pressure and confining pressure (OD in Figure 8), the equal decrease in axial pressure and confining pressure (OE in Figure 8), and so on. For example, when studying the deformation and strength characteristics of marble under different confining pressure rates, Qiu et al. [30] selected the OC path, while Zhao et al. [23] chose the OE path, resulting in different deformation laws of rock specimens. Therefore, it is necessary to choose a matching unloading path according to the actual research requirement and situation. The focus of this study is on the variation of the mechanical properties of rock during the gradual increase of axial stress and the reduction of confining pressure. Therefore, the path of increasing axial pressure while unloading confining pressure is selected in this study, that is, the OB path shown in Figure 8.

The detailed test procedures are defined as follows:

(1) Increase axial pressure and confining pressure to $5 \mathrm{MPa}$ at a constant rate simultaneously

(2) The axial compression was applied to the conventional uniaxial compression peak strength of $65 \mathrm{MPa}$ at a constant rate in a stress-controlled way

(3) The confining pressure was removed at the rate of $0.1 \mathrm{MPa} / \mathrm{s}$ with increasing axial pressure at the rate of $0.5 \mathrm{MPa} / \mathrm{s}$ until specimen failure

The stress-strain curve and the final destroyed rock sample are shown in Figures 6(b) and 7(d), respectively. The axial strain increases slowly in the triaxial compression tests under unloading confining pressure condition, which is reduced by half as compared to the conventional triaxial compression test. In the initial stage of unloading confining pressure, the circumferential strain gradually increases linearly with a growth rate of approximately 3 to 5 times of the one of the axial strain. With the continuous unloading confining pressure, the lateral strain rapidly increases, which indicates that the cracks have begun to be generated and gradually penetrated through the rock samples. At this point, a small change in a confining pressure may cause greater lateral and axial deformation, indicating that the rock has entered the failure stage. During the process of unloading confining pressure, the volume strain rapidly changes from positive to negative, showing obvious lateral expansion. After 


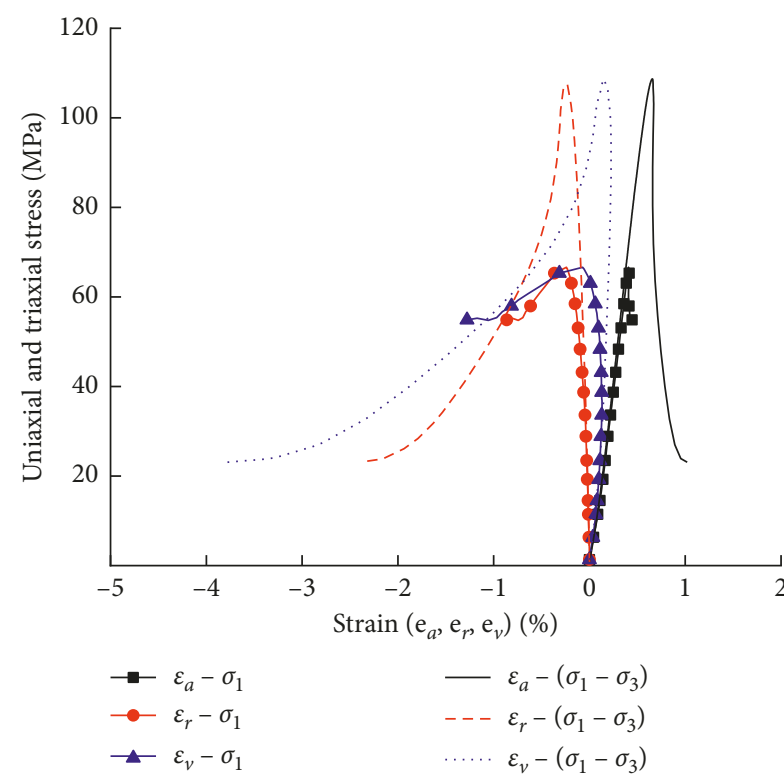

(a)

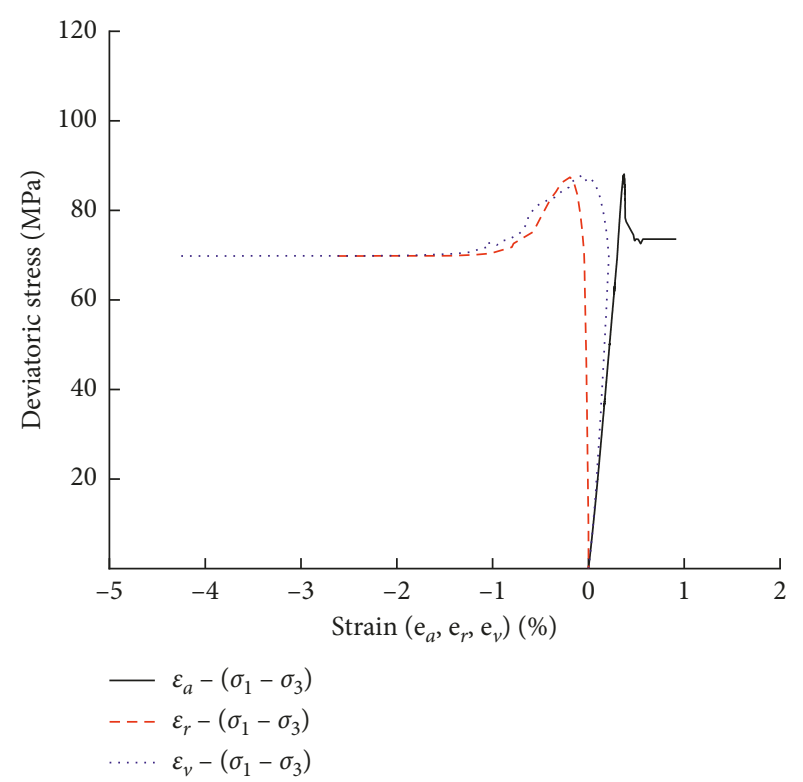

(b)

FiguRE 6: Stress-strain curves. (a) Stress-strain curves of uniaxial and triaxial compression tests. (b) Stress-strain curves of triaxial compression tests under unloading confining pressure condition.

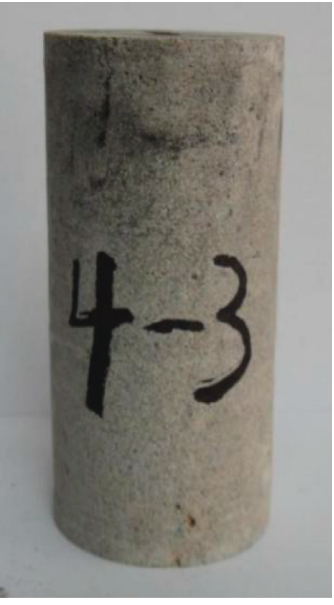

(a)

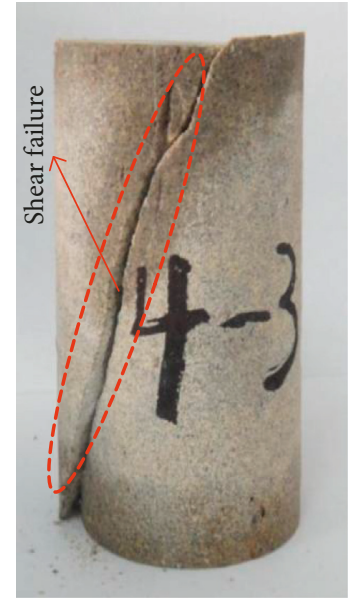

(b)

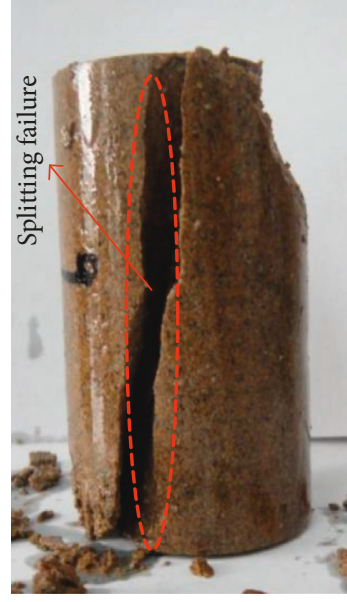

(c)

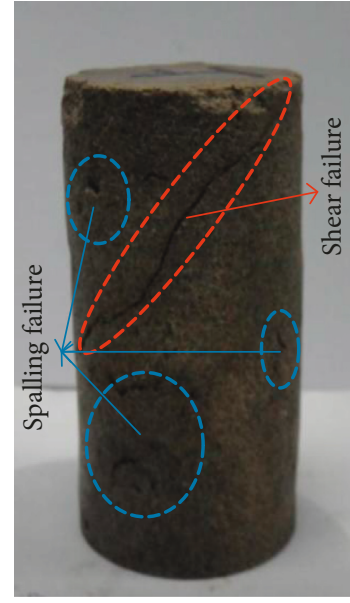

(d)

Figure 7: Typical test results of rock. (a) Rock samples. (b) Conventional triaxial compression failure mode. (c) Uniaxial compression failure mode. (d) Triaxial compression failure mode with unloading confining pressure.
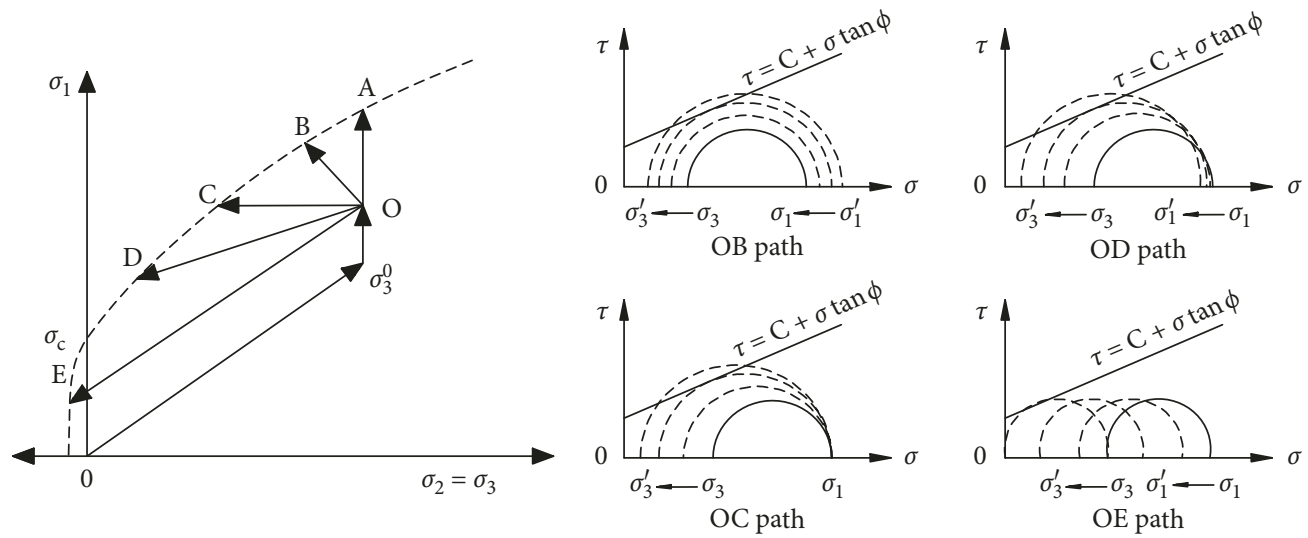

FIGURE 8: Stress path of unloading confining pressure. 
the peak strength, there is obvious circumferential deformation and volume deformation. The reduction of the confining pressure from $5 \mathrm{MPa}$ to 0 indicates that the rock mass undergoes three-dimensional stress state to uniaxial stress state. The peak intensity of sandstone is higher than the conventional uniaxial compression peak intensity and lower than that of the conventional triaxial test, which is about $80 \%$. For the failure mode of samples, the uniaxial compression test shows a splitting failure and the conventional triaxial compression test shows shear failure with the shear plane penetrating the entire sample, while the triaxial compression test with unloading confining pressure displays shear failure with the splitting crack parallel to the axial direction on the sample surface. This can be explained as the unloading confining pressure of rock samples is equivalent to a tensile stress exerted on the circumferential surface of the rock sample, resulting in the fracture parallel to the axial direction. The fracture gradually expands internally due to the action of tensile stress, resulting in a large lateral deformation, that is, the lateral dilatancy phenomenon shown in Figure 5(b).

\section{Unloading Damage Mechanical Model of Fractured Rock Mass}

During the long-term formation of geological bodies, various structural planes with different shapes and sizes are formed within the rock mass by the diagenesis and tectonization. To some extent, the mechanical properties of rock mass are controlled by these structural planes. In other words, the destruction of the rock mass is essentially the process of interaction and expansion of structural planes. After the rock excavation, stress concentrations may be formed near the crack tip for the internal primary cracks under the unloading stress field consisting of the initial stress (compressive stress) and the unloading stress (tensile stress), causing the cracks to expand unstably.

Consider an existing series of equal-width and straightline collinear cracks oriented at an angle $\beta$ and propagating at an angle $\theta_{0}$ inside the rock. Setting the origin at the midpoint of any crack, a local $x-y$ coordinates system with one axis along the crack is stabled (shown in Figure 9). Assume the crack length of $2 a$, the center distance of the adjacent cracks of $2 b$, the vertical stress as $\sigma=\gamma(H+\Delta H)$, and the horizontal stress as $\lambda \sigma-\Delta \sigma$, where, $\gamma$ is the average bulk density of overburden, $H$ is the mining depth, $\Delta H$ is the dumping height, $\lambda$ is the lateral pressure coefficient, and $\Delta \sigma$ is the unloading stress.

The normal stress component $\sigma_{\beta}$ and the tangential shear stress component $\tau_{\beta}$ at the crack tip are obtained, respectively,

$$
\begin{aligned}
\sigma_{\beta} & =\left(\frac{\sigma_{1}+\sigma_{3}}{2}+\frac{\sigma_{1}-\sigma_{3}}{2} \cos 2 \beta\right) \\
& =\gamma(H+\Delta H)\left(\lambda \sin ^{2} \beta+\cos ^{2} \beta\right)-\Delta \sigma \sin ^{2} \beta, \\
\tau_{\beta} & =\frac{\sigma_{1}-\sigma_{3}}{2} \sin 2 \beta=[\gamma(H+\Delta H)(1-\lambda)+\Delta \sigma] \sin \beta \cos \beta .
\end{aligned}
$$

Due to the unloading stress, the opening-sliding failure occurs under the joint action of normal stress $\sigma_{\beta}$ and shear stress $\tau_{\beta}$, which can be regarded as the combination of opening mode caused by unloading stress and sliding mode caused by initial stress, i.e., Mixed-Mode I-II. According to the principle of superposition, in many instances, stress intensity solutions for complex configurations can be built from simple cases. So, cracks tip stress fields in the polar coordinates for the Mixed-Mode I-II portion of the loading are given as

$$
\begin{aligned}
\sigma_{r r} & =\frac{1}{2 \sqrt{2 \pi r}}\left[K_{\mathrm{I}}(3-\cos \theta) \cos \frac{\theta}{2}+K_{\mathrm{II}}(3 \cos \theta-1) \sin \frac{\theta}{2}\right], \\
\sigma_{\theta \theta} & =\frac{1}{2 \sqrt{2 \pi r}} \cos \frac{\theta}{2}\left[K_{\mathrm{I}}(1+\cos \theta)-3 K_{\mathrm{II}} \sin \theta\right] \\
\tau_{r \theta} & =\frac{1}{2 \sqrt{2 \pi r}} \cos \frac{\theta}{2}\left[K_{\mathrm{I}} \sin \theta+K_{\mathrm{II}}(3 \cos \theta-1)\right]
\end{aligned}
$$

where $K_{\mathrm{I}}, K_{\mathrm{II}}$ are the stress intensity factors in Mode I and Mode II, respectively, which are defined as

$$
\begin{aligned}
& K_{\text {I }}=\sigma_{\beta} \sqrt{\pi a}\left(\frac{2 b}{\pi a} \tan \frac{\pi a}{2 b}\right)^{1 / 2}, \\
& K_{\text {II }}=\tau_{\beta} \sqrt{\pi a}\left(\frac{2 b}{\pi a} \tan \frac{\pi a}{2 b}\right)^{1 / 2} .
\end{aligned}
$$

According to the maximum circumferential stress criterion [31], the mixed-mode crack is propagated in the direction where the circumferential stress $\sigma_{\theta \theta}$ is maximum. The circumferential stress field around the tips of the crack front can be formulated in terms of the stress intensity factors:

$$
\begin{array}{r}
\sigma_{\theta \theta}=\frac{1}{\sqrt{2 \pi a}}\left[\frac{K_{\mathrm{I}}}{4}\left(3 \cos \frac{\theta}{3}+\cos \frac{3 \theta}{2}\right)\right. \\
\left.+\frac{K_{\mathrm{II}}}{4}\left(-3 \sin \frac{\theta}{2}-3 \sin \frac{3 \theta}{2}\right)\right] .
\end{array}
$$

The direction of the maximum circumferential stress is expressed by

$$
\left.\frac{\partial \sigma_{\theta \theta}}{\partial \theta}\right|_{\theta=\theta_{0}}=0 .
$$

Substituting equation (5) into equation (6) leads to

$$
K_{\mathrm{I}} \sin \theta_{0}+K_{\mathrm{II}}\left(3 \cos \theta_{0}-1\right)=0,
$$

and the fracture criterion is

$$
\left[K_{\mathrm{I}} \cos ^{2} \frac{\theta_{0}}{2}-\frac{3}{2} K_{\mathrm{II}} \sin \theta_{0}\right] \cos \frac{\theta_{0}}{2}=K_{\mathrm{IC}} .
$$

Substituting equations (1), (3), and (4) into equation (7) gives the relationship between crack propagation angle $\theta_{0}$ and crack dip angle $\beta$ under unloading: 


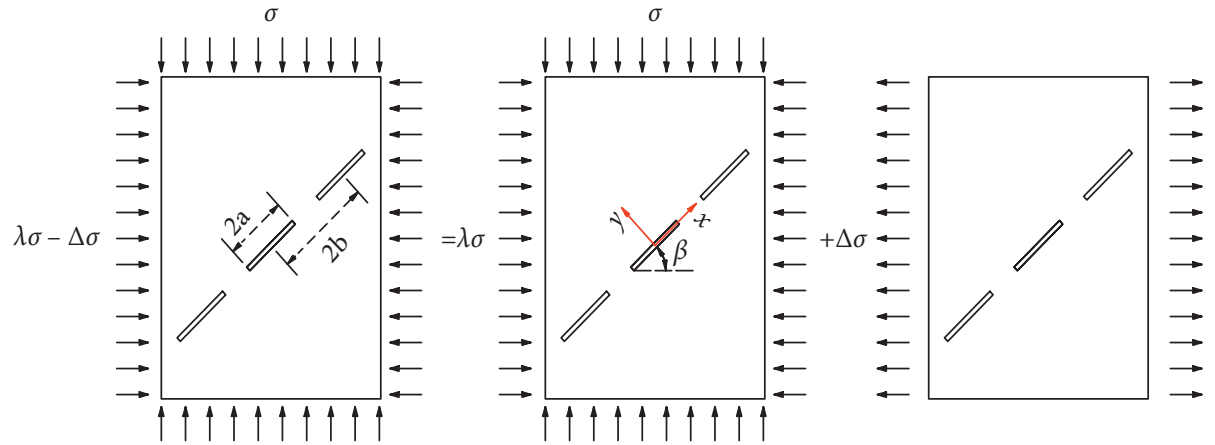

Figure 9: Unloading stress field.

$\frac{\gamma(H+\Delta H)\left(\lambda \sin ^{2} \beta+\cos ^{2} \beta\right)-\Delta \sigma \sin ^{2} \beta}{[\gamma(H+\Delta H)(1-\lambda)+\Delta \sigma] \sin \beta \cos \beta}=\frac{1-3 \cos \theta_{0}}{\sin \theta_{0}}$.

Replacing $\left(\gamma(H+\Delta H)\left(\lambda \sin ^{2} \beta+\cos ^{2} \beta\right)-\Delta \sigma \sin ^{2} \beta\right) /$ $([\gamma(H+\Delta H)(1-\lambda)+\Delta \sigma] \sin \beta \cos \beta)$ with $A$ in equation (10) yields

$$
\theta_{0}=\arccos \frac{3 \pm \sqrt{A^{4}+8 A^{2}}}{A^{2}+9}
$$

From the stress distribution in the composite slope (shown in Figure 4), it is known that the unloading stress is equivalent to applying a reverse tensile stress based on the initial stress and gradually decreasing to 0 , i.e., $\Delta \sigma \in[0, \lambda \gamma H]$. Putting $\Delta \sigma_{\max }=\lambda \gamma H$ in equation (9) gives

$$
\frac{1-3 \cos \theta_{0}}{\sin \theta_{0}}=\frac{\gamma H \cos ^{2} \beta+\gamma \Delta H\left(\lambda \sin ^{2} \beta+\cos ^{2} \beta\right)}{[\gamma H+\gamma \Delta H(1-\lambda)] \sin \beta \cos \beta} \text {. }
$$

For a special case $\Delta H=0$, which means there has been no stripped materials dumping along the side of the slope after excavation, equation (11) becomes

$$
\frac{1-3 \cos \theta_{0}}{\sin \theta_{0}}=\cot \beta
$$

Figure 10 illustrates the effect of a crack dip angle $\beta$ on the crack propagation angle $\theta_{0}$ by equation (12). It is known that the slope excavation results in the instantaneous release of lateral restraint and the crack initiation under the vertical

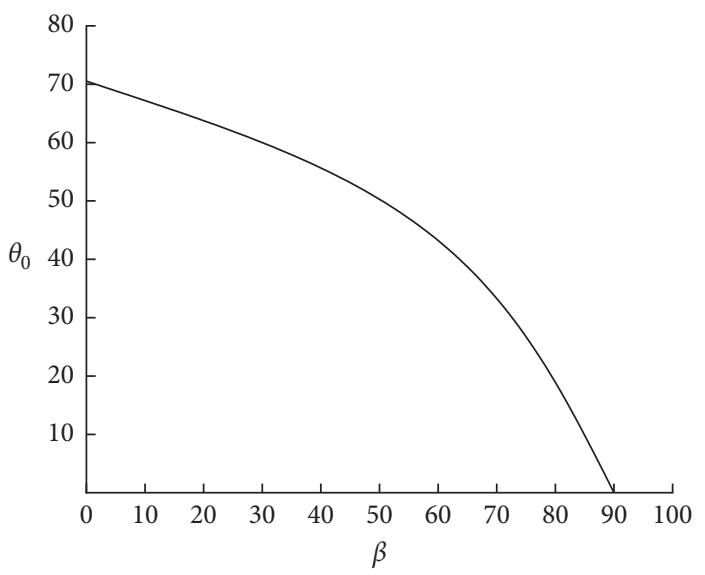

Figure 10: Curve of the crack propagation angle and crack dip angle.

stress. The propagation angle $\theta_{0}$ gradually decreases with the increase of the crack dip angle $\beta$. Note that when $\beta=90 \%$, propagation occurs in the crack plane $\left(\theta_{0}=0\right)$ since the crack lies on a principal plane and is subjected to pure Mode I loading, showing the splitting failure in the uniaxial compression test. On the contrary, a small crack dip angle $\beta$ results in a larger propagation angle $\theta_{0}$ which tends to be perpendicular to the direction of the maximum principal stress.

Substituting equations (3), (4), and (9) into equation (8) gives

$$
H+\Delta H=\frac{2 K_{\mathrm{IC}}}{\gamma \sqrt{\pi a} \cos \left(\theta_{0} / 2\right)((2 b / \pi a) \operatorname{tag}(\pi a / 2 b))^{1 / 2}\left[\left(1+\cos \theta_{0}\right) \sin ^{2} \beta-3 \sin \theta_{0} \sin \beta \cos \beta\right]} .
$$

The analytic relation of limit height $H+\Delta H$ of a composite slope with other known parameters is built up. It shows that if these parameters are given, the corresponding limit height $H+\Delta H$ of composite slope can be obtained when the crack propagation occurs near the slope surface under the unloading stress field.

\section{Discussion}

From equation (13), the analytic relation in the limit height $H+\Delta H$ of the composite slope with other known parameters is built up. It shows that if those parameters are given, the corresponding limit height $H+\Delta H$ of composite slope can 
be obtained when the crack propagation occurs near the slope surface under the unloading stress field. The factors affecting the limit height of the composite slope mainly includes the crack initial length $2 a$, adjacent crack distance $2 b$, crack dip angle $\beta$ (as well as the corresponding crack propagation angle $\theta_{0}$ given by equation (11)), average bulk density $\gamma$ of overburden, and fracture toughness $K_{\mathrm{IC}}$, where fracture toughness is a property which describes the ability of a material to resist a crack fracture. These are the inherent properties of rock material like bulk density and can be classified as fixed factors independent of the size and shape of the crack itself. It can be seen from equation (13) that the ultimate height preforms a linear relationship with the fracture toughness and the average bulk density of overburden. That is, the greater the fracture toughness, the stronger the ability of the rock mass to withstand the fracture, while the greater the average bulk density of overburden, the greater the vertical normal stress, which is conducive to the cracking of the rock mass. Generally, the hard rock mass has a corresponding lager fracture toughness. Therefore, the effect of the fixed factor on the ultimate height is not obvious.

The variable factors like crack initial length $2 a$, adjacent crack distance $2 b$, and crack dip angle $\beta$ are the parameters that represent the frequency and shape of the crack distribution, whose distribution directly affects the strength, permeability and anti-freeze-thaw weathering ability of engineering rock mass. In order to obtain the distribution of cracks in the coal seam at the bottom of the compound slope of BP Mine, a horizontal drilling hole with aperture of $32 \mathrm{~mm}$ was drilled in the middle of the coal seam. The results of borehole observation show that the mine has simple stratum structure under small tectonic movement. Cracks are mainly distributed near the entrance of the borehole, in the way of high frequency and short spacing cluster with long spacing cracks scattered randomly and irregularly among clusters. The approximate interval of the frequency and shape parameters of the cracks in the coal seam was obtained by borehole peeper. For BP Mine, $a=0-4 \mathrm{~cm}$, $\beta=48-76^{\circ}, \quad \gamma=23 \mathrm{kN} / \mathrm{m}^{3}$, and $K_{\mathrm{IC}}=0.2 \mathrm{MPa} \cdot \mathrm{m}^{1 / 2}$. Some video screenshots are shown in Figure 11.

The limit heights of a composite slope at different crack dip angles are shown in Figure 12. The curves show that the variation of limit height with the crack dip angle is consistent, showing a significant trend of decreasing first and then increasing. The limit height in all curves attains minimum value when the crack dip angle is around $62^{\circ}$. In open-pit mining, the slope angle of a single step is generally set between 60 and $65^{\circ}$ to prevent slope collapse. Therefore, it can be seen that when the crack dip angle in the rock is gradually parallel to the step slope, the decomposition force perpendicular to the crack is gradually reduced, which easily tends to cracking and expansion of cracks under unloading force. Cracks parallel to the slope of step are more susceptible to unloading fracture. Meanwhile, it can be seen that when the crack length $(2 a)$ is constant, the limit height of the composite slope increases slowly with the increase in adjacent crack distance. While the crack distance $(2 b)$ is fixed, the limit height decreases greatly with the increase of the

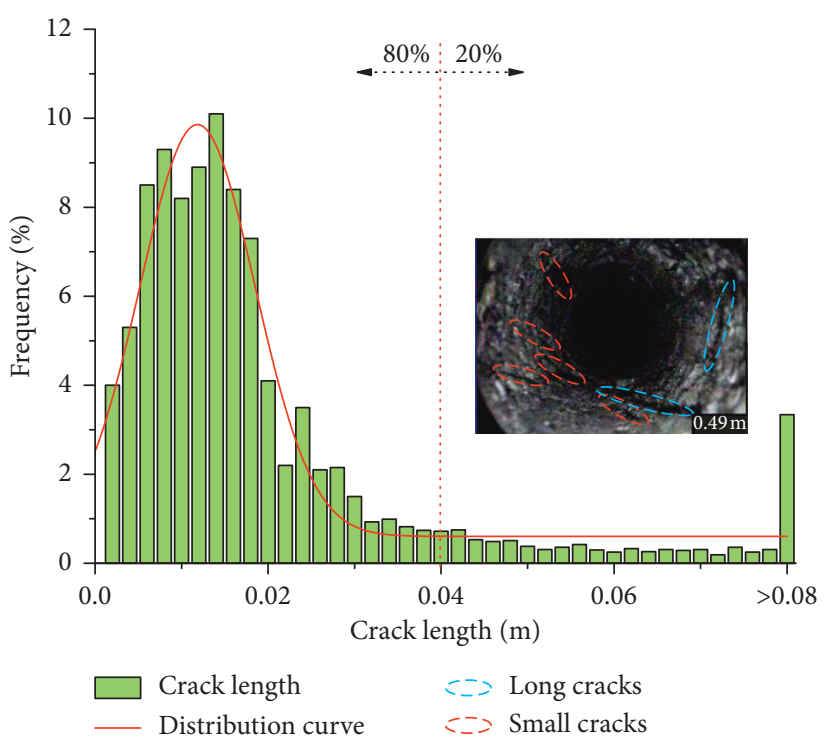

FIgURE 11: Probability distribution of crack length.

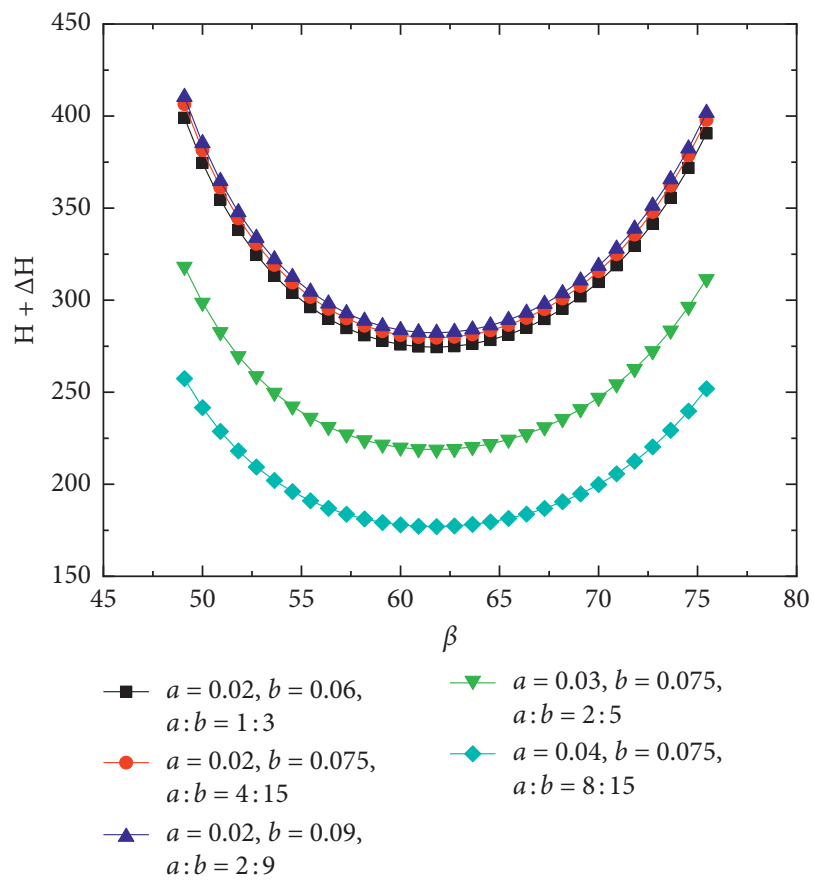

FIgURE 12: The limit heights of composite slope under different crack dip angles.

crack length, which is reduced from $279.5 \mathrm{~m}$ to $177 \mathrm{~m}$. The change of crack length has a more significant effect on the limit height of the composite slope.

The crack frequency is an important indicator of the degree of crack development in geotechnical engineering, which can be expressed as the ratio of the average crack distance to the crack length, i.e., $b: a$. It can be seen from any single curve in Figure 13 that the limit height of the composite slope is logarithmically related to the crack frequency, that is, when the crack length is fixed, cracks with dense distribution are more likely to cause unloading fracture. Specifically, when the crack frequency is between 1 and 2 , the 


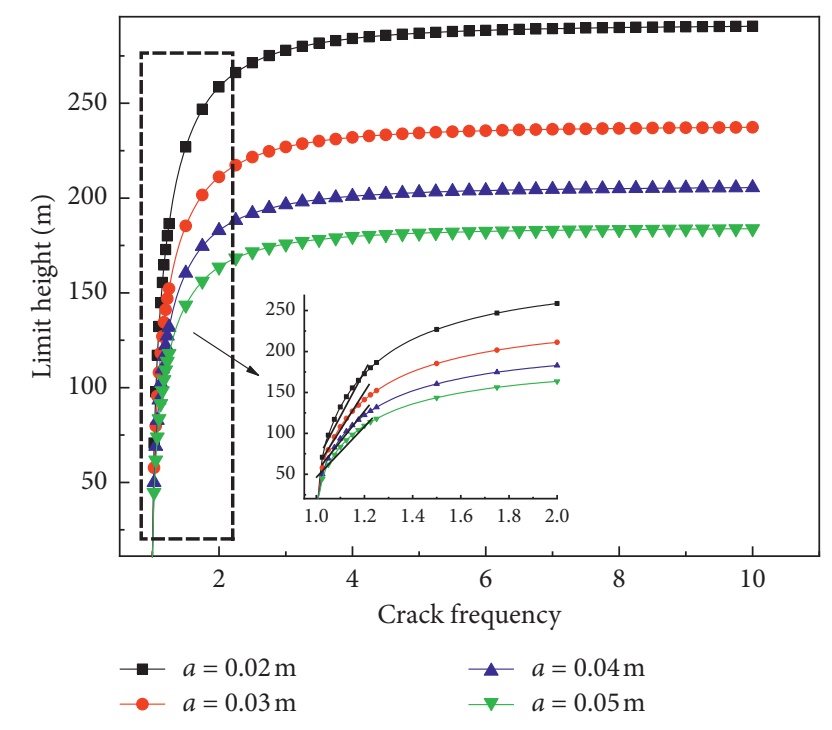

FIgURE 13: The limit heights of composite slope under different crack frequencies.

variation of limit height is the most significant. At this time, the adjacent crack distance is smaller than the crack length itself, and the insufficient strength of effective resistance to fracture is liable to lead to penetration failure between cracks. The dashed box in the figure indicates that the limit height varies greatly with the change of the crack length. As the crack length increases, the slope of limit height increasing with crack frequency becomes smaller. After the balance, the long fractured rock mass is more prone to unloading fracture; when the crack frequency is between 2 and 4 , the variation of the limit height gradually decreases, and the elastic core region of the rock mass increases gradually between adjacent cracks, which is not easy to break; when the crack frequency is greater than 4 , the curve shape gradually becomes horizontal. The limit height is close to a fixed value and the size tends to be stable; that is, the unloading fracture between adjacent cracks can be regarded as independent, with little influence on each other. It can also be seen from Figure 13 that when the crack frequency is a fixed value, the larger the crack length of the rock mass, the smaller the limit height of the corresponding composite slope. At this point, the crack scale determines whether it cracks in the unloading stress field. In other words, when the height of the composite slope is constant, stress concentration is generated at the crack tip under the action of the unloading stress field. If the unloading stress is greater than the cracking strength of the rock mass, the crack will initiate along the direction of the crack tip, which will promote the expansion of the original crack length. However, if the unloading stress is not greater than the ultimate tensile stress of rock mass cracking, the crack will not propagate directly but will form a progressive damage zone at the crack tip. When the fatigue damage accumulates to a certain extent, new cracks will gradually propagate. The factors leading to the damage include frost heave force caused by the phase change of crack water, vibration effect of surrounding rock bench blasting, etc.
In summary, regarding high-steep composite slopes in open-pit mine, stress concentration occurs within the composite slope with the gradual increase of excavation depth and the dumping height. The closer slope surface leads to a greater unloading effect, and the closer slope bottom results in higher upper loading effect. When the composite slope height exceeds the limit height (calculated by equation (13)), cracks in the rock body may expand, penetrate, and even develop to macrofracture damage, causing the entire slope landslide.

\section{Conclusions}

This paper revealed that the stress state of rock mass near the composite slope surface undergoes the process of "triaxial stress $\rightarrow$ horizontal unloading $\rightarrow$ axial loading." The horizontal unloading stress is equivalent to applying a reverse tensile stress on the initial stress and gradually decreasing to 0 . The stress concentrations may be formed near the crack tip for the internal primary cracks under the unloading stress field consisting of the initial stress (compressive stress) and the unloading stress (tensile stress), causing the cracks to expand unstably. The rock compression tests under different stress paths showed that the deviatoric stress required for sandstone unloading failure is higher than that of the uniaxial compression strength and lower than that of the conventional triaxial compression strength. The lateral strain of rock samples increases with the increasing unloading, showing an obvious lateral dilatancy phenomenon. After slope excavation, the stress concentrations may be formed near the crack tip for the internal primary cracks under the unloading stress field consisting of the initial stress (compressive stress) and the unloading stress (tensile stress), causing the Mixed-Mode I-II cracks to expand unstably. By constructing the mechanics model of the crack under loading-unloading stress field, the analytic relation of limit height for composite slope with the crack length, adjacent width, and crack dip angle as the variation is determined when the crack propagation occurs near the slope surface.

\section{Data Availability}

The data used to support the findings of this study are available from the corresponding author upon request.

\section{Conflicts of Interest}

The authors declare that there are no conflicts of interest.

\section{Acknowledgments}

This research was funded by the National Key Research and Development Program of China (2016YFC0501100), the General Program of National Natural Science Foundation of China (51574222), and the Natural Science Foundation of Xinjiang Province of China (2018D01A42). The authors are grateful to all the generous support. 


\section{References}

[1] M. F. Ashby and S. D. Hallam, "The failure of brittle solids containing small cracks under compressive stress states," Acta Metallurgica, vol. 34, no. 3, pp. 497-510, 1986.

[2] Q. Feng, B. Jiang, G. Wang, and C. Hu, "Analytical solution for a circular roadway considering the transient effect of excavation unloading," International Journal of Mining Science and Technology, vol. 26, no. 4, pp. 543-549, 2016.

[3] C. Scavia, "Fracture mechanics approach to stability analysis of rock slopes," Engineering Fracture Mechanics, vol. 35, no. 45, pp. 899-910, 1990.

[4] Q. Cai, W. Zhou, J. Shu, Y. Liu, and H. Peng, "Analysis and application on end-slope timeliness of internal dumping under flat dipping ore body in large surface coal mine," Journal of China University of Mining and Technology, vol. 37, no. 6, pp. 740-744, 2008.

[5] D. Verma, R. Thareja, A. Kainthola, and T. N. Singh, "Evaluation of open pit mine slope stability analysis," International Journal of Earth Sciences and Engineering, vol. 4, no. 4, pp. 590-600, 2011.

[6] X. P. Zhou, "Localization of deformation and stress-strain relation for mesoscopic heterogeneous brittle rock materials under unloading," Theoretical and Applied Fracture Mechanics, vol. 44, no. 1, pp. 27-43, 2005.

[7] J. Fu, W. Song, and Y. Tan, "Criterion of local energy release rate of gob instability in deep mines considering unloading stress path," International Journal of Mining Science and Technology, vol. 27, no. 6, pp. 1011-1017, 2017.

[8] H. Yang, J. Liu, and X. Zhou, "Effects of the loading and unloading conditions on the stress relaxation behavior of precracked granite," Rock Mechanics and Rock Engineering, vol. 50, no. 5, pp. 1157-1169, 2017.

[9] D. Huang, H. Jin, and R. Huang, "Mechanism of fracture mechanics and physical model test of rocks crack expanding under tension-shear stress," Rock and Soil Mechanics, vol. 32, pp. 997-1002, 2011.

[10] L. Han, W. Zhou, J. Shu, S. Wang, and Q. Meng, "Study of plane sliding timeliness stability and structure optimization of soft rock slope," Journal of China University of Mining and Technology, vol. 43, pp. 395-401, 2014.

[11] P. K. Kaiser, S. Yazici, and S. Maloney, "Mining-induced stress change and consequences of stress path on excavation stability-a case study," International Journal of Rock Mechanics and Mining Sciences, vol. 38, no. 2, pp. 167-180, 2001.

[12] J. Chen, D. Jiang, S. Ren, and C. Yang, "Comparison of the characteristics of rock salt exposed to loading and unloading of confining pressures," Acta Geotechnica, vol. 11, no. 1, pp. 221-230, 2016.

[13] B. Fu, M. Tu, and M. Gao, "Study on unloading instability model of working face with large mining height," Journal of Mining \& Safety Engineering, vol. 34, no. 6, pp. 1128-1133, 2017.

[14] W. Cao, X. Li, M. Tao, and Z. Zhou, "Vibrations induced by high initial stress release during underground excavations," Tunnelling and Underground Space Technology, vol. 53, pp. 78-95, 2016.

[15] Q. Zhang, X. Fan, Y. Liang et al., "Mechanical behavior and permeability evolution of reconstituted coal samples under various unloading confining pressures-implications for wellbore stability analysis," Energies, vol. 10, no. 3, p. 292, 2017.

[16] H. Huang, P. Fan, J. Li, M. Wang, and X. Rong, "A theoretical explanation for rock core disking in triaxial unloading test by considering local tensile stress," Acta Geophysica, vol. 64, no. 5, pp. 1430-1445, 2016.

[17] J. B. Martino and N. A. Chandler, "Excavation-induced damage studies at the underground research laboratory," International Journal of Rock Mechanics and Mining Sciences, vol. 41, no. 8, pp. 1413-1426, 2004.

[18] T. Shimamoto, "Confining pressure reduction experiments: a new method for measuring frictional strength over a wide range of normal stress," International Journal of Rock Mechanics and Mining Sciences \& Geomechanics Abstracts, vol. 22, no. 4, pp. 227-236, 1985.

[19] Y. Wang, X. Li, B. Zheng, S. Li, and Y. Duan, "A laboratory study of the effect of confining pressure on permeable property in soil-rock mixture," Environmental Earth Sciences, vol. 75, no. 4, p. 284, 2016.

[20] H. Haeri, A. Khaloo, and M. F. Marji, "A coupled experimental and numerical simulation of rock slope joints behavior," Arabian Journal of Geosciences, vol. 8, no. 9, pp. 7297-7308, 2014.

[21] L. Ma, K. Li, S. Xiao, and X. Ding, "Optimisation study on coordinated mining model of coal reserves buried between adjacent surface mines," International Journal of Oil, Gas and Coal Technology, vol. 16, no. 3, pp. 283-297, 2017.

[22] P. Rongkun, F. Dong, Y. Minggao, and C. Lei, "Directivity effect of unloading bedding coal induced fracture evolution and its application," International Journal of Mining Science and Technology, vol. 27, no. 5, pp. 825-829, 2017.

[23] G. Zhao, B. Dai, L. Dong, and C. Yang, "Experimental research on mechanical characteristics and strength criterion of rock of triaxial unloading tests under different stress paths," Rock and Soil Mechanics, vol. 36, pp. 3121-3127, 2015.

[24] D. Deng, L. Liang, and L. Zhao, "Critical position of tensile cracks and stability analysis in slope near river," Journal of Central South University, vol. 44, no. 9, pp. 3873-3883, 2013.

[25] R. Ulusay, M. Ekmekci, E. Tuncay, and N. Hasancebi, "Improvement of slope stability based on integrated geotechnical evaluations and hydrogeological conceptualisation at a lignite open pit," Engineering Geology, vol. 181, pp. 261-280, 2014.

[26] C. Herrero, Quantifying the EFFECT of in-situ stresses and pit depth on slope stability by incorporating brittle fracturing in numerical model analyses, Ph.D. thesis, Colorado School of Mines, Golden, CO, USA, 2015.

[27] C. D. Martin, "Seventeenth Canadian geotechnical colloquium: the effect of cohesion loss and stress path on brittle rock strength," Canadian Geotechnical Journal, vol. 34, no. 5, pp. 698-725, 1997.

[28] E. C. Kalkani, "Excavation unloading effect in rock wedge stability analysis," Canadian Geotechnical Journal, vol. 14, no. 2, pp. 258-262, 2011.

[29] T. R. Stacey, Y. Xianbin, R. Armstrong, and G. J. Keyter, "New slope stability considerations for deep open pit mines," Journal of the South African Institute of Mining and Metallurgy, vol. 103, no. 6, pp. 373-389, 2003.

[30] S. Qiu, X. Feng, C. Zhang, H. Zhou, and F. Sun, "Experimental research on mechanical properties of deep-buried marble under different unloading rates of confining pressures," Chinese Journal of Mechanical Engineering, vol. 29, pp. 1807-1817, 2010.

[31] F. Erdogan and G. C. Sih, "On the crack extension in plates under plane loading and transverse shear," Journal of Basic Engineering, vol. 85, no. 4, pp. 519-595, 1963. 


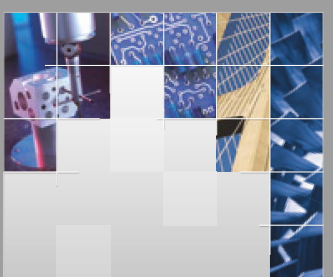

\section{Enfincering}
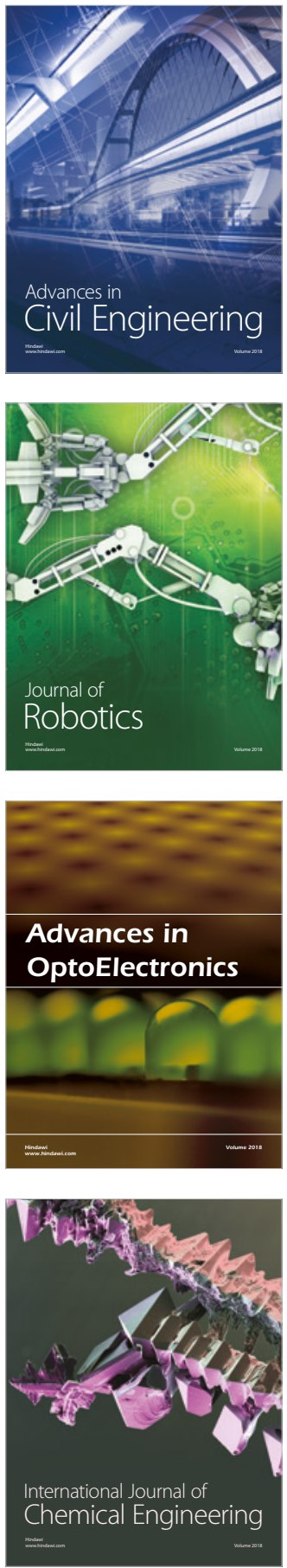

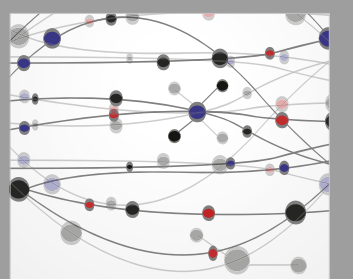

\section{Rotating \\ Machinery}

The Scientific World Journal

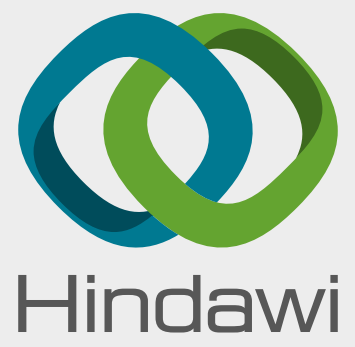

Submit your manuscripts at

www.hindawi.com
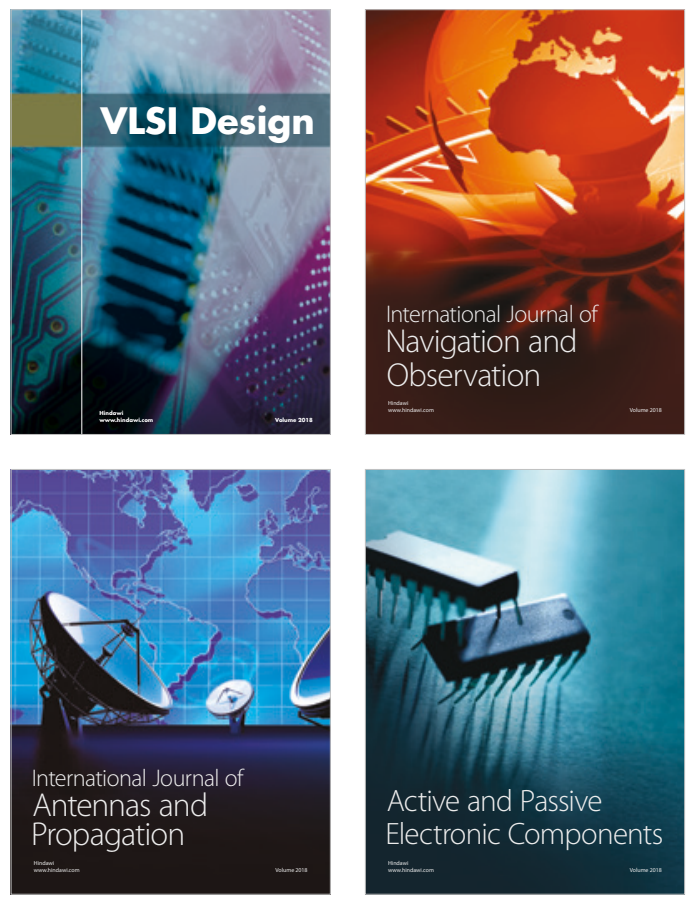
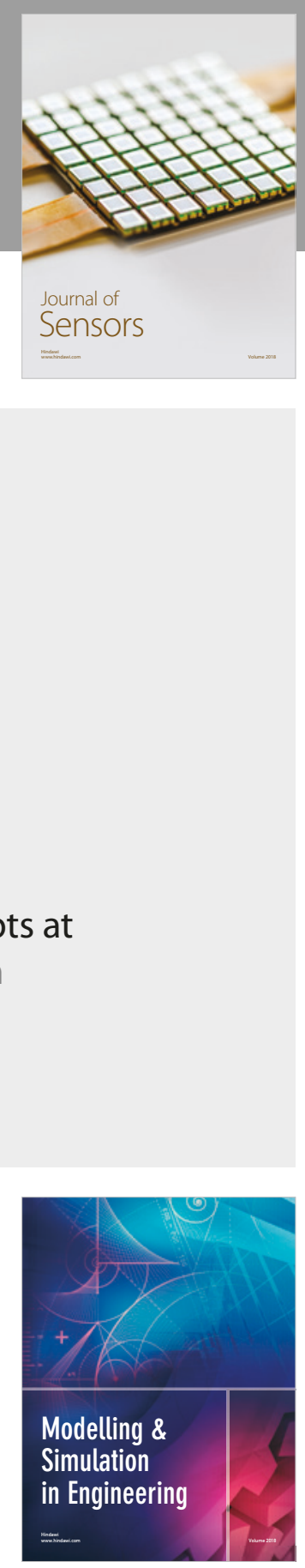

\section{Advances \\ Multimedia}
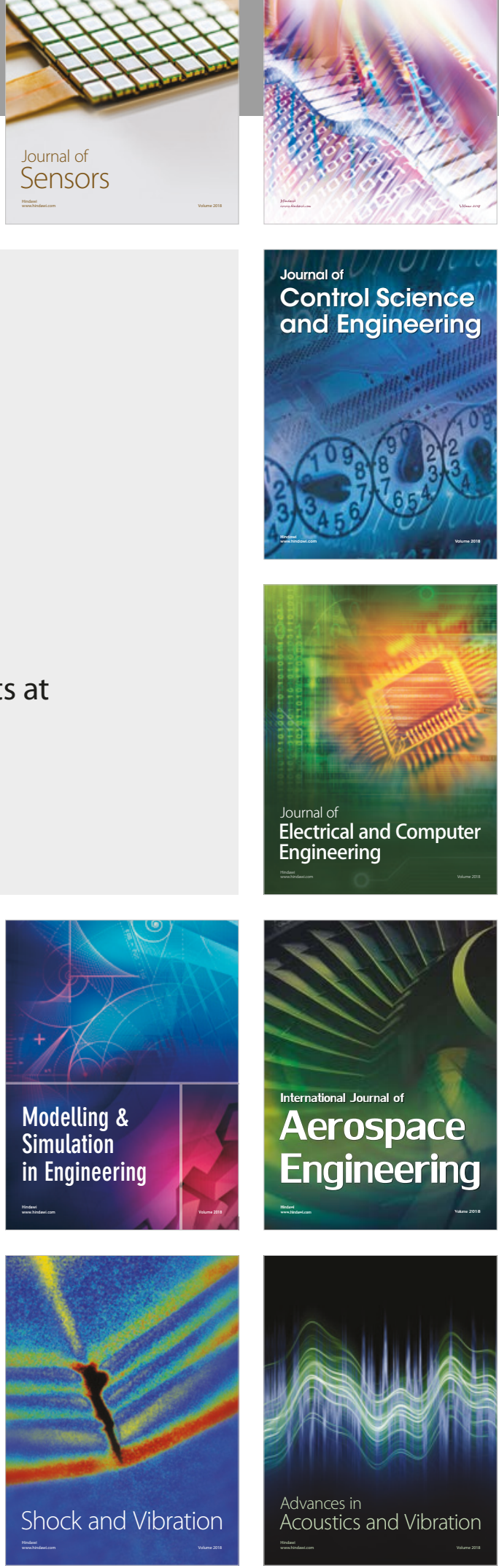